\title{
Understanding Research and Scientific Publication
}

\author{
Ganesh Dangal, ${ }^{1}$ Pawan Kumar Hamal, ${ }^{1}$ Mona Giri ${ }^{1}$ \\ 1Journal of Nepal Health Research Council, Kathmandu, Nepal
}

Any research work is completed only after completion of the final step which is "dissemination". Even though the philosophy of publish or perish has been well accepted by the scientific community for a long time, till date, for most of the researchers, dissemination has been limited to sharing of the findings to their colleagues or to the audience at the local, regional or national conferences. ${ }^{1}$

The major reason behind the emphasis on publication has been the fact that until and unless any research work gets published, the findings would be confined to the researcher and there would be no proof to validate the work. ${ }^{1}$ Further, publications help researchers to share their work to the larger scientific community and get feedback. The real essence of publication is the sharing of discoveries and ideas to the wider network and learning what others have already found in the specific area and get insights on what more needs to be searched. It is to be internalized that if the research works were not shared, the progress in scientific world would be slow and negligible. ${ }^{2}$

Besides, in recent years, with reference to professional growth, publication has become one of the major criteria for being hired, getting promoted or being funded for future research. ${ }^{3}$ In the context of Nepal too, the universities have made publication a criteria for academic positions. ${ }^{2}$ This has proved to be one of the measures to promote the research and publication culture. However, compulsion to publish a research paper for upliftment in the professional career has also become one of the major hurdles for some of the professionals, one of the major reasons being lack of skills to write up their research work in a correct and concise form. Majority of the professionals want their work to get published only for the sake of academic designation and these faculties would neither teach nor encourage the new generation to conduct research and publish the evidence generated. ${ }^{4}$
Based on the reflections of the editors and reviewers of most of the journals in Nepal, one of the most essential areas to be improved is the skills of the authors to present their work in precise format. ${ }^{2}$ Before embarking on the race to get ones name in the most prestigious journals, one should be acquainted with writing skills. The next step could be to share their work within their peers to get the feedback. Feedback from the peer group helps the most to evaluate one's own work and to identify the shortcoming and hence refine the writing. This review could then be followed by identification of the appropriate audience for the study finding and after that the choice of journal shall be determined. ${ }^{5}$

Many a times, the researches often lack readers because of the choice of the journals. Rather than aiming for most popular journals, one should target to get their work read by large number of people and this could be achieved by publishing the article in quality national journals or speciality journals based on the nature of the research work and the findings. It is to be realized that publication is not only the dissemination of findings and results, it is the means to present ones arguments based on the research work and recommend appropriate policies. This underlines the importance of choice of the right journal for publication. ${ }^{6}$

Moreover, the fear of rejection from the journal acts as the factor for reservedness of the researchers. The fact that most established academicians also get rejected should be born in mind and researcher should be aware of the fact that reason for rejection is not always the poor quality of research. The paper might not have fallen into the priority areas of the journal, or it might not be the appropriate read for its readers. ${ }^{5}$

Thus, the current trend to publish only for the sake of meeting the criteria for professional growth needs to be changed and the real need to research and publish should be embraced by all the enthusiastic researchers 
which could in the long run be beneficial to the scientific community and could add on to the evidences.

\section{REFERENCES}

1. Day RA, Gastel B. How to write and publish a scientific paper: $7^{\text {th }}$ Ed. California, USA: ABC-CLIO, LLC; 2011. p. 230.

2. Magar A. Scientific publications in Nepal. J Nepal Health Res Counc. 2012 Sep;10(22):243-9. [PubMed]
3. Coolidge HJ, Lord RH. Archibald Cary Coolidge, life and letters. USA: Houghton Mifflin Company; 1932.

4. Marusić M, Marusić A. Good editorial practice: editors as educators. Croat Med J. 2001;42(2):113-20. [PubMed]

5. Anderson L, Bonds-Raacke J, Raacke J. Looking to succeed? Understanding the importance of research publications.Psychology Student Network ; 2015 [cited 2017 April 26]. [Link]

6. Jaensch C. Why submit? Why publish? Why review?. UK: University of Essex; [cited 2017 April 26]. [Full Text] 